\title{
Stepwise Refolding of Acid-Denatured Myoglobin: Evidence from Electrospray Mass Spectrometry
}

\author{
Rong Feng and Yasuo Konishi \\ National Research Council of Canada, Biotechnology Research Institute, Montreal Quebec, Canada
}

\begin{abstract}
Application of electrospray mass spectrometry (ES/MS) to a protein refolding study was demonstrated. Acid denaturation of equine myoglobin was reversed by adding various amounts of ammonium hydroxide to the protein that was unfolded in $10 \%$ acetic acid. The protein refolding process was followed by ES/MS, in which both the changes in the protein charge-state distribution and mass were monitored. The ES/MS results show that the $\mathrm{pH}$-dependent renaturation of the acid-denatured myoglobin is stepwise, consisting of two major steps. The unfolded polypeptide chain first refolds to establish a compact nativelike structure, without the assistance of the heme prosthetic group. The newly formed binding cavity then retains the heme group by noncovalent interactions. It is also shown that inclusion of a stabilizing buffer, such as ammonium acetate, in the protein solution is greatly beneficial to the ES/MS detection of intact noncovalent globin/heme complex. (J Am Soc Mass Spectrom 1993, 4, 638-645)
\end{abstract}

$\mathrm{T}$ The conformation of a protein in solution can be altered by changing $\mathrm{pH}$, ionic strength, solvent composition, and temperature, etc. The conversion from the native state to a denatured one renders the protein biologically inactive because the tertiary and secondary structures [1-4] of the native protein have been partially or completely destroyed. Such conformational changes are reversible for some proteins but not for others. Studying protein denaturation (i.e., unfolding) and refolding processes is important not only for deducing the fundamental structure/property correlations [1-4], but also for understanding the cellular responses of various biological systems and for efficient production of biologically active recombinant proteins [5]. Various instrumental methods, such as $x$-ray crystallography $[1-4]$, circular dichroism $[3,6,7]$, proton nuclear magnetic resonance $[1,3,6,8,9]$, infrared and Raman spectroscopy [3], and cyclic voltammetry $[10,11]$, have been used for protein conformational studies.

Electrospray mass spectrometry (ES/MS) [12-16], which offers high measurement precision $[17,18]$ and has an analytical mass range as high as $200,000 \mathrm{Da}$ for proteins [19], has demonstrated great versatility in various biochemical studies, such as characterizing protein primary structures [20-23], enzyme reaction intermediates [24, 25], inhibition mechanisms [26], and

A major part of this work was first presented at the 40th ASMS Conference on Mass Spectrometry and Allied Topics, Washington, DC, May 31-June 5, 1992 (abstr P 1635)

Address reprint requests to Rong Feng, National Research Council of Canada, Biotcchnology Research Institute, 6100 Royalmount Aventue, Montreal, Quebec H4P 2R2, Canada. covalent [24-27] and noncovalent [28] enzyme complexes. It has also been shown [29-34] that the characteristic electrospray multicharging, which usually forms one (or more) charge-state distribution in the mass-to-charge ratio range $500-2500$, is sensitive to protein conformational changes in solution. This unique feature of electrospray further extends the capability of mass spectrometry for biochemical characterization because it provides the potential to study the three-dimensional structures of proteins.

In this article we report a novel utilization of ES/MS for studying protein refolding in which the $\mathrm{pH}$-dependent renaturation process of the acid-denatured myoglobin is followed by monitoring the changes in both the charge-state distribution and the mass of the protein. The mechanistic significance of the ES/MS findings in relation to the myoglobin refolding process is also discussed.

\section{Experimental}

\section{Mass Spectrometry}

A triple quadrupole mass spectrometer (API III, Sciex, Thornhill, Ontario, Canada) was used for the ES/MS study. The instrument had a mass-to-charge ratio range of 2470 and was fitted with a pneumatically assisted electrospray (also referred to as ion spray [16]) device. Multiply charged protein ions were generated by spraying the aqueous sample solution at room temperature and under atmospheric pressure. The electrosprayer, a stainless steel capillary [200- $\mu \mathrm{m}$ inner diam- 
eter (ID)] held $+4.8 \mathrm{kV}$ above the instrument ground potential, was assisted by a coaxial air flow $(0.6 \mathrm{~L} / \mathrm{min})$ along the capillary; the pressure in the aeronebulizer was set to $20 \mathrm{lb} / \mathrm{in}^{2}$. The sample solution was delivered at a flow rate of $1-2 \mu \mathrm{L} / \mathrm{min}$ to the electrosprayer by a syringe infusion pump (model 22, Harvard Apparatus, South Natick, MA) through a fusedsilica capillary of $100-\mu \mathrm{m}$ ID. The electrospray-produced ions, driven by the voltage ditterence between the sprayer and the instrument body, migrated under atmospheric pressure toward the ion entrance orifice (approximately $100 \mu \mathrm{m}$ in diameter) at the atmosphere/vacuum interface. A gas curtain formed by a continuous flow $(1.2 \mathrm{~L} / \mathrm{min})$ of nitrogen gas around the conical orifice served to prevent moisture from entering the vacuum chamber and to cause a very large number of near-thermal collisions in the postorificc free-jet expansion region and in the quadrupole guidance lens $\left(Q_{0}\right)$ in front of the first quadrupole mass analyzer $\left(Q_{1}\right)$.

For ion mass measurement, the instrument orifice voltage was set at $+35 \mathrm{~V}$ during the mass-to-charge ratio calibration with the singly charged ammonium adduct ions of poly(propylene glycols) and then increased to $+80 \mathrm{~V}$ to enhance the myoglobin ion signals, unless otherwise stated. The inn-molecule collisions in the atmosphere/vacuum interface region, which were energized by the elevated orifice voltage, stripped off the solvent molecules attached to the myoglobin ions and produced the bare protein ions for mass-to-charge ratio analysis. To induce ion structural changes by the interface collisions $[20,22]$, the orifice voltage was further raised to between +130 and +250 $\mathrm{V}$ to boost the ion internal energy uptake. For the mass spectrometry studics conducted here, only the $Q_{1}$ quadrupole was utilized for the ion mass-to-charge ratio analysis, and all other quadrupoles of the triple quadrupole mass spectrometer served as the ion guidance lenses.

\section{Materials and Sample Handling}

Horse skeletal muscle myoglobin and its heme-less counterpart, apomyoglobin, were obtained from Sigma Chemical Co. (St. Louis, MO) and were used without further purification. To detect the intact noncovalently bound complex ions of the native myoglobin, the protein sample was sprayed as an aqueous solution at a concentration of $1.7 \mathrm{mg} / \mathrm{mL}\left(1 \times 10^{-4} \mathrm{M}\right)$, with 10 $\mathrm{mM}$ ammonium acetate as the stabilizing buffer ( $\mathrm{pH}$ 6.7) unless otherwise stated. To release the heme group from the noncovalent binding, the native myoglobin was acid denatured by mixing the buffered sample solution with an equal volume of $20 \%(\mathrm{v} / \mathrm{v})$ acetic acid solution, reaching a solution acidity of $10 \%$ acetic acid ( $\mathrm{pH} 2.2$ ) and reducing the protein concentration to $5 \times 10^{-5} \mathrm{M}$. To effect the refolding of the acid-denatured myoglobin, the solution acidity was reduced by adding various amounts of ammonium hydroxide of concentrations $3-9 \%(\mathrm{w} / \mathrm{w})$, raising the solution $\mathrm{pH}$ to as high as 8 , and further decreasing the protein concentration to as low as $2 \times 10^{-5} \mathrm{M}$. Ammonium acetate buffer was produced as a result of the acid/base neutralization reaction between acetic acid and ammonium hydroxide. To avoid temperature- and solventinduced denaturation, all experiments were carried out at room temperature, and organic solution modifiers, such as popularly used methanol or acetonitrile, were not used in any of the above experiments.

\section{Results and Discussion}

The native form (the state before denaturation or after complete refolding) of myoglobin is composed of two parts (i.e., the proteinic globin main body, a single polypeptide chain of 153 amino acid residues and mass $16,951 \mathrm{Da}$, and the organometallic heme prosthetic group, an iron protoporphyrin IX of mass 616.5 Da). Myoglobin is biologically functional (i.e., capable of storing oxygen) only after the heme group is retained within the binding cavity of the folded globin by multiple van der Waals interactions [1, 2, 35-38]. Therefore, detecting the intact ions of the noncovalently bound globin/heme complex under the ES/MS experimental conditions $[30,34]$ is essential to the full-range study of the myoglobin refolding process. In an earlier effort [34] to study the native globin/heme complex, the equine myoglobin sample was dissolved in pure water at neutral $\mathrm{pH}$, at which the protein maintained a native conformation; however, under such a solvent condition, a substantial amount of the native globin/heme complex would often dissociate during the electrospray ionization, as evidenced by the abundant heme-less ions from the polypeptide portion of myoglobin in the electrospray mass spectrum (Figure 1). It was suspected that the ionic polarization of the solution by the high voltage on the electrosprayer, and the subsequent proton enrichment in the nebu-

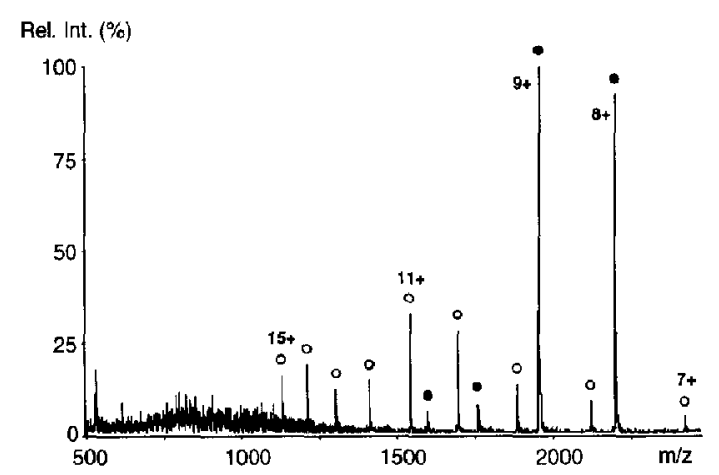

Figure 1. Electrospray mass spectrum of equine myoglobin dissolved in pure water: (O) ions from the noncovalently bound globin/heme complex (mass $17,568 \mathrm{Da}$ ); $(\mathrm{O})$ ions from the heme-less globin part (mass 16,951 Da). The charge states (i.e., the number of hydrogen cations) on a few representative multicharge ions are indicated. 
lized microdroplets during the solvent evaporation under atmospheric pressure, could have caused partial denaturation of the protein, leading to the detachment of the heme group from the noncovalent complex. Hence, in the ensuing experiments the myoglobin sample was instead dissolved in a buffer solution containing $10 \mathrm{mM}$ ammonium acetate ( $\mathrm{pH}$ 6.7) in the hope that the pH-regulating effect of the buffer would stabilize the protein during the electrospray ionization. This revised approach, much as expected, nearly completely eliminated the unwanted denatured myoglobins ions, producing a clean spectrum dominated by the ions from the undissociated globin/heme complex of mass 17,568 Da (Figure 2a). [Although the concentration of ammonium acetate was more than two orders of magnitude higher than that of myoglobin in the solution, it was surprising that formation of ammonium adducts to the protein ions remained insignificant (Figure 2a). In sharp contrast, sodium or potassium salts were often a nuisance to the ES/MS analysis because of the high tendency of their cations to stick to the protein. These noncovalent cation adducts added long tails to the protein peaks (see Figure $2 \mathrm{a}$, inset) and could not be completely removed by the gas-phase collisional activation in the atmosphere/vacuum interface region, even when the orifice voltage was raised to its maximum value of $+250 \mathrm{~V}$.] Similar to the previous observations made under the unbuffered weakly acidic [30] and neutral [34] solution conditions, the charge-state distribution of the native myoglobin, which was dominated by the $8^{+}$and $9^{+}$ ions (Figure $2 a$ ), was drastically different from that of the myoglobin denatured in $10 \%$ acetic acid $(\mathrm{pH} 2.2)$, which centered around $18^{+}$and extended to as high as $29^{+}$(Figure 2b).

In solution, the positive charges of a protein are mainly located on the side-chain amino groups of the basic residues, such as arginine (Arg), lysine (Lys), and histidine (His) ( $\mathrm{p} K_{\mathrm{a}}$ values of which, in the free state, are $12.5,10.5$, and 6.0 , respectively; see ref $2, p 79$ ), and the negative charges on the side-chain carboxylic groups of the acidic residues, such as aspartic acid (Asp) and glutamic acid (Glu) ( $\mathrm{pK}$ a values of which, in the free state, are 3.9 and 4.3 , respectively; see ref 2 , $p$ 79). Among the 153 amino acid residues in equine myoglobin, 32 are basic (2 Arg, $19 \mathrm{Lys}$, and $11 \mathrm{His})$, and 21 are acidic ( $8 \mathrm{Asp}$ and 13 Glu). X-ray crystallographic data $[2,35-38]$ show that in the native myoglobin, all chargeable residues of both polarities, except for the two buried His residues that sandwich the heme group, are placed on the solvent/proton-accessible molecular surface; however, under the ES/MS conditions, mainly 8 and 9 net positive charges were observed for the native myoglobin (Figures 1 and 2a). These low-charge states, which sharply contrasted with the high-charge states of the acid-denatured myoglobin (Figure 2b), could not be attributed to instrumental effects because the operating parameters were kept identical during the experiments. In addition,
Rel. Int. (\%)
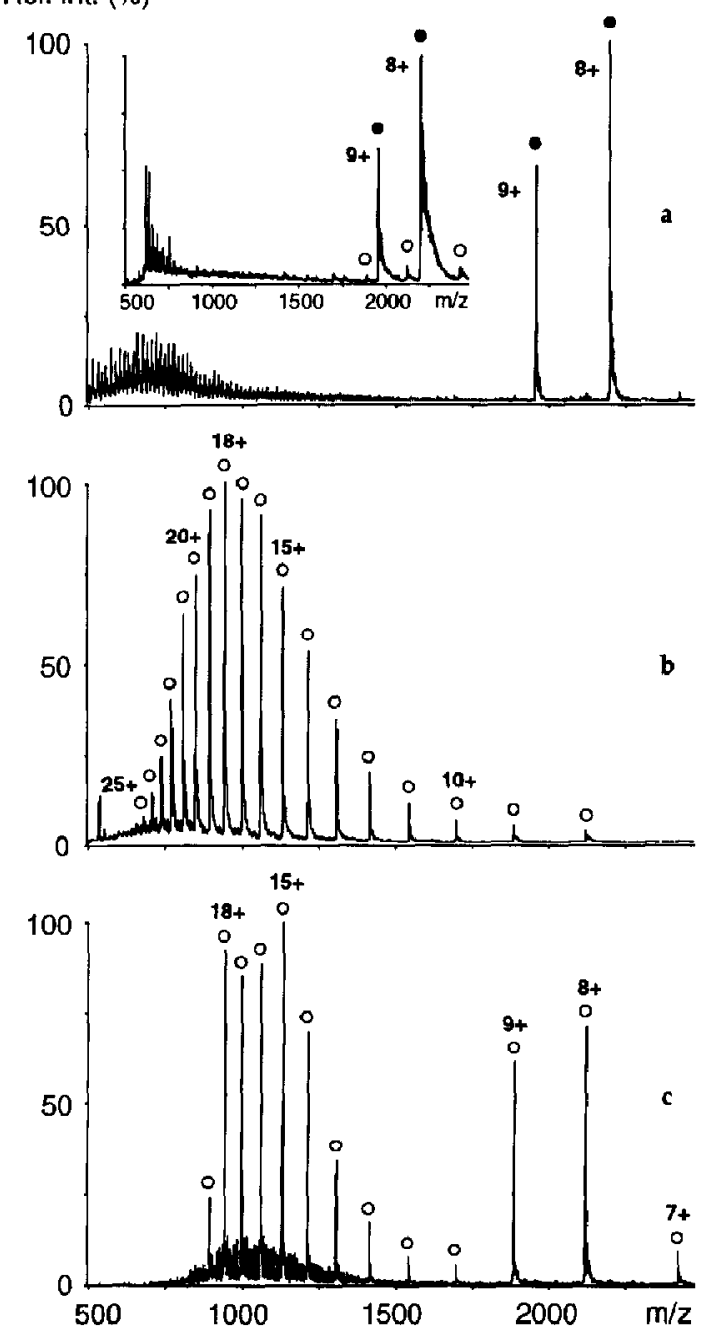

Figure 2. (a) Electrospray mass spectrum of equine myoglobin dissolved in a buffer solution containing $10 \mathrm{mM}$ ammonium acetate $(\mathrm{pH} 6.7)$. The mass integrity of the native globin/heme complex was nearly fully preserved (orifice voltage $+80 \mathrm{~V}$ ), as indicated by the predominant ions of the charge states $8^{+}$and $9^{+}$ (O), which retained the heme prosthetic group (mass 616.5 Da). Inset, spectrum taken under the same buffer condition but at a higher orifice voltage $(+100 \mathrm{~V})$ for a myoglohin sample contaminated with potassium salt. The broad tails of the protein peaks were caused by the potassium cation adducts, and the minor peaks (O) were due to the ions that lost the heme group at the higher orifice voltage. (b) Electrospray mass spectrum of the same sample as in (a) but denatured by adding acetic acid to a final concentration of $10 \%(\mathrm{pH} \mathrm{2.2)}$. The charge-state distribution of the multiply charged ions (O) shifted to high-charge-state (low mass-to-charge ratio) region in addition to losing the heme group. (c) Electrospray mass spectrum of "partially renatured" equine myoglobin. The protein was first denatured in $10 \%$ acetic acid, and then the solution $\mathrm{pH}$ was raised to 5 by adding ammonium hydroxide. A second charge-state distribution $\left(7^{+}-9^{+}\right)$, whose ions had no heme attachment, appeared at massto-charge ratio $1800-2470$. 
varying the orifice voltage in the range +30 to $+100 \mathrm{~V}$ (data not shown) did not produce drastic changes in the charge distribution pattern of either the native or acid-denatured myoglobin (however, in the orifice voltage range +30 to $+50 \mathrm{~V}$, the protein peaks were very broad, with peak widths at half height as large as $1400 \mathrm{Da}$ in the molecular weight scale due to insufficient collisional desolvation of these gaseous ions at low activation energies). Although the charge-state distribution of the acid-denatured myoglobin was shifted moderately toward the high mass-to-charge ratio region at increased solution $\mathrm{pH}$ (Figure $2 \mathrm{~b}, \mathrm{c}$ ), only minor profile alterations (data not shown) were registered for the charge-state distribution of the native myoglobin from $\mathrm{pH} 5$ to 10 . Therefore, the lowcharge states of the native myoglobin could not be simply due to the decreased concentration of hydrogen ions in solution at higher $\mathrm{pH}$. More likely, the structural features of the native myoglobin had restricted the maximum number of net charges that the molecule could carry while still maintaining its conformational integrity. It appeared, in solution at least, that at the native conformation the negative charges on the 21 acidic residues had counteracted the positive charges on the 30 exposed basic residues, resulting in fewer net positive charges (mainly $8^{+}$and $9^{+}$ions observed in the gas phase) on the myoglobin molecule. Such an analysis, which does not rule out possible modifications to the original charge-state distribution by other forces during the electrospray and ion transportation processes, is consistent with the general observation [29-34] that the gaseous ions from a protein having the native solution conformation always carry fewer charges than those from its denatured counterpart.

At the native conformation, the polypeptide chain of myoglobin curls into a roughly spherical shape in which a cavity is left open to trap the heme group. The molecular interior, which is almost entirely composed of nonpolar amino acid residues, except for two histidines, is extremely compact and fits the heme group very tightly with little extra space [2, 35-38]. The higher mass observed for the native myoglobin in the ES/MS experiment leaves no doubt that the heme group remains attached to the polypeptide chair, everl after the multiply charged ions have been ejected into the gas phase by the high electric field on the evaporating microdroplets. Although it remains open to speculation (and further experimentation) whether the key features of the heme-binding pocket have survived the solution-to-gas-phase transition, the heme attachment, and the high mass-to-charge ratio charge-distribution profile that is characteristic of proteins at their native conformational states [29-34], can be taken as an indication that these gaseous globin/heme complex ions have originated from the myoglobin species having the native conformation in solution [30, 34].

To gain a better understanding of the refolding process, it is advantageous to first look at its counterprocess denaturation because these two molecular transitions are closely related to each other, and useful information about the former can often be obtained by studying the latter. Acid denaturation completely or partially destroys the tertiary and secondary structures of the native myoglobin in solution. Such structural changes greatly diminish the heme-binding capability of the polypeptide chain, resulting in the release of the trapped heme group and thus in the reduction of the protein mass (Figure 2b). The drastic shift of the charge-state distribution to the low mass-to-charge ratio (high-charge state) region (Figure 2b), which is usually accompanied by broadening of the charge-state distribution, is another direct consequence of protein denaturation [29-34].

Inspection of the myoglobin x-ray structural model reveals that at the native conformation, approximately 14 positively charged side-chain amino groups of Arg and Lys residues are paired at the intercharge distances of 2.4-5.0 $\AA$, with an equal number of negatively charged side-chain carboxylic groups of Asp and Glu residues. These electrostatically interacting intramolecular ion pairs (often called salt bridges or salt links $[3,36]$ in the biochemical literature), along with hydrogen bonds and hydrophobic interactions, stabilize the tertiary structure of the native protein $[2,3]$. At low $\mathrm{pH}$, the increased solution acidity, which neutralizes the negative charges on the carboxylic groups [3, 39] and unveils the counteracting positive charges on the amino groups, disrupts the inn pairs and causes the protein to unfold. The relaxed myoglobin polypeptide chain after denaturation also exposes other buried chargeable sites, such as the interior His residues, for protonation. Furthermore, a denatured protein is physically capable of holding more charges simply because its greatly increased molecular volume has substantially reduced the Coulombic repulsion among the charges. For example, a fully stretched-out myoglobin polypeptide chain occupies one order of magnitude more space than one that is compactly folded in the native state [36]. Therefore, the multiple actions of acid denaturation, such as unveiling the masked positive charges, exposing the hidden chargeable sites, and enlarging the molecular volume, bring a substantial charge increase to the prutein and shift the charge-state distribution to the high-charge-state (low mass-tocharge ratio) region (Figure $2 \mathrm{~b}$ ). Depending on the degree of neutralization among the negatively charged carboxylic groups (alone or in ion pairs), the number of net positive charges would also vary on acid denaturation. Such an effect may have contributed to the broadening of the charge-state distribution of the acid-denatured myoglobin (Figure 2b).

To reverse the denaturation of the native myoglobin caused by the high concentration of acetic acid (10\% $\mathrm{v} / \mathrm{v}, \mathrm{pH} 2.2$ ), various amounts of ammonia hydroxide were added to the protein solution to reduce its acidity. Of interest, when the solution $\mathrm{pH}$ reached 5, a nativelike charge-state distribution emerged in the high mass-to-charge ratio region (Figure $2 c$ ); however, the 
ions in this new charge-state distribution remained heme-less. It appears that as a result of the decrease in solution acidity, structural changes in a direction opposite to the chair unfolding and extension caused by acid denaturation, such as chain twisting and contraction, may have occurred to the myoglobin polypeptide chain in addition to removing the protons from the carboxylic groups that are in the neutral state and the amino groups that are positively charged. The high mass-to-charge ratio charge-state distribution of the "partially renatured" myoglobin (Figure 2c) is similar to that of the native myoglobin (Figure 2a), possibly because the solution conformation of the former resembles that of the latter.

Remarkably, when the solution $\mathrm{pH}$ was further increased to the range $6-8$, the heme group became reattached to the polypeptide (Figure 3 ). At $\mathrm{pH} \mathrm{6,a}$ large fraction of the polypeptide became heme bound (Figure 3b), and the relative intensities of the heme-less high-charge-state ions in the denatured charge-state distribution (mass-to-charge ratio 800-1600, not shown) were further reduced to $\leq 50 \%$ of the new base peak $\left(8^{+}\right)$intensity. At $\mathrm{pH} 8$, the heme rebinding appeared to be nearly complete (Figure $3 c$ ) because only a very small fraction of the heme-less ions remained in the high mass-to-charge ratio region shown, and no appreciable ion signals of the denatured myoglobin could be detected in the region below mass-to-charge ratio 1600. Among the covalent side attachments to the heme central ring are the two vinyl groups and two propionic acids that are potentially susceptible to chemical reactions with certain functional groups under some special conditions; however, covalent binding between the heme group and the myoglobin polypeptide chain at $\mathrm{pH} 6^{-8}$ can be ruled out on scveral lines of cvidence. First, under the room temperature and nearneutral $\mathrm{pH}$ conditions used, formation of covalent bond(s) between the heme group and certain side-chain groups of the polypeptide appeared very unlikely because these conditions were well within the myoglobin stability region (up to $80^{\circ} \mathrm{C}$ and between $\mathrm{pH} 5$ and 11 [39]). Second, reacidifying the solution immediately caused the protein to shed the heme group in addition to shifting the charge-state distribution back to the low mass-to-charge ratio region. Third, slightly energizing the desolvation collisions between the myoglobin ions and the nitrogen curtain gas in the atmosphere/vacuum interface region $[20,22,40]$ easily removed the heme group in the gas phase (Figure 4a). Similar to the native myoglobin (Figure $4 \mathrm{~b}$ ), the collisional release of the heme group from (i.e., the "gasphase denaturation" of) the renatured myoglobin (Figure 4a) required very little activation, at which no cleavage of the covalent bonds in the polypeptide chain could be detected. In fact, knocking off the heme group needed somewhat less activation energy than collisionally stripping the noncovalent sulfate adducts [40] from the heme-containing ions of a less pure myoglobin sample. (The binding strength between a
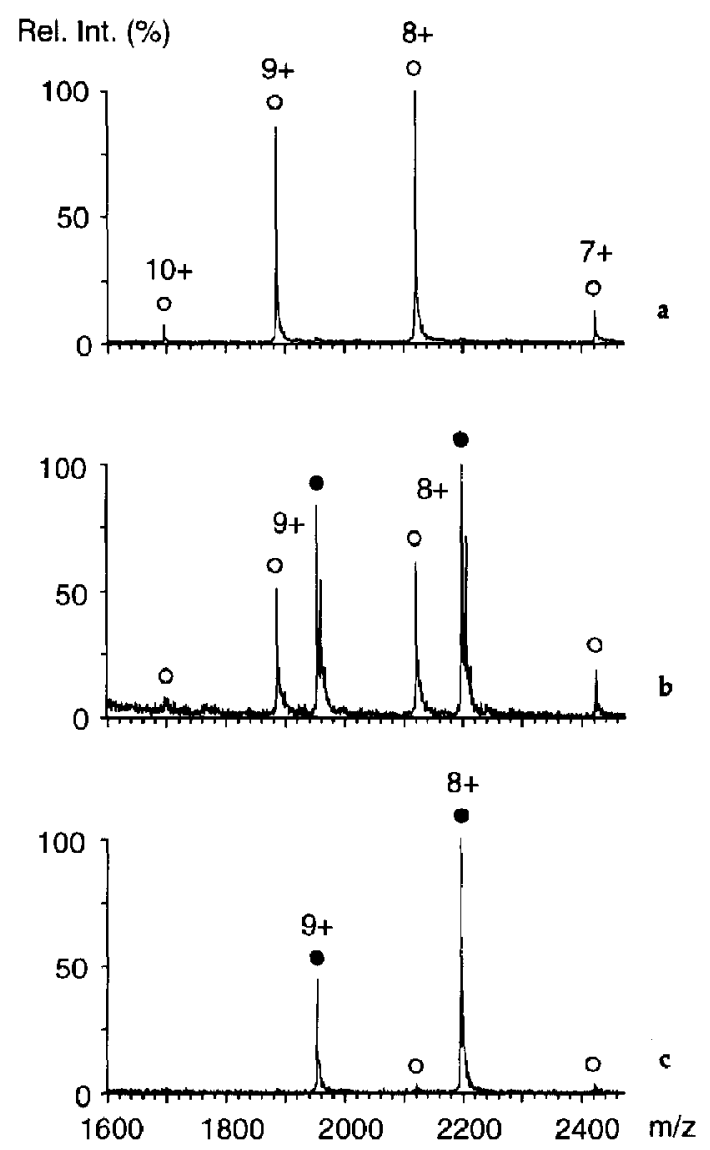

Figure 3. Partial electrospray mass spectra of equine myoglobin at mass-to-charge ratio 1600-2470 containing ions of the charge states $7^{+}-10^{+}$. The charge-state distributions in the high massto-charge ratio region, which resembled that of the native globin/heme complex in Figure $2 a$, were produced by adding various amounts of ammonium hydroxide to the denatured protein in $10 \%$ acetic acid. The spectra were taken at $\mathrm{pH} 5$ (a), 6 (b), and $8(\mathrm{c}) ;(\Theta)$ peaks due to the noncovalent reattachment of the heme group to the polypeptide chain at higher $\mathrm{pH}$ is; satellite peaks on the right side of the two heme-containing peaks in $\mathbf{b}$ were due to acetate adducts.

sulfate and a protein appears to be smaller than that of a covalent bond because sulfate adducts can usually be removed under mild collision conditions without causing fragmentation of a polypeptide chain [40]; and $\mathrm{x}$-ray crystallographic data [38] show that the sulfate interacts with the molecular surface of the native myoglobin via hydrogen bonds.) As shown in Figure 4c, some myoglobin ions that were intentionally infested with ammonium sulfate in solution retained their noncovalent sulfate attachments in the gas phase, even after they had released the heme group at the increased orifice voltage. The facile release of the repossessed heme group, both in solution by reacidification and in the gas phase by collisional activation, showed that the heme reattachment at the near-neutral 
Rel. Int. (\%)
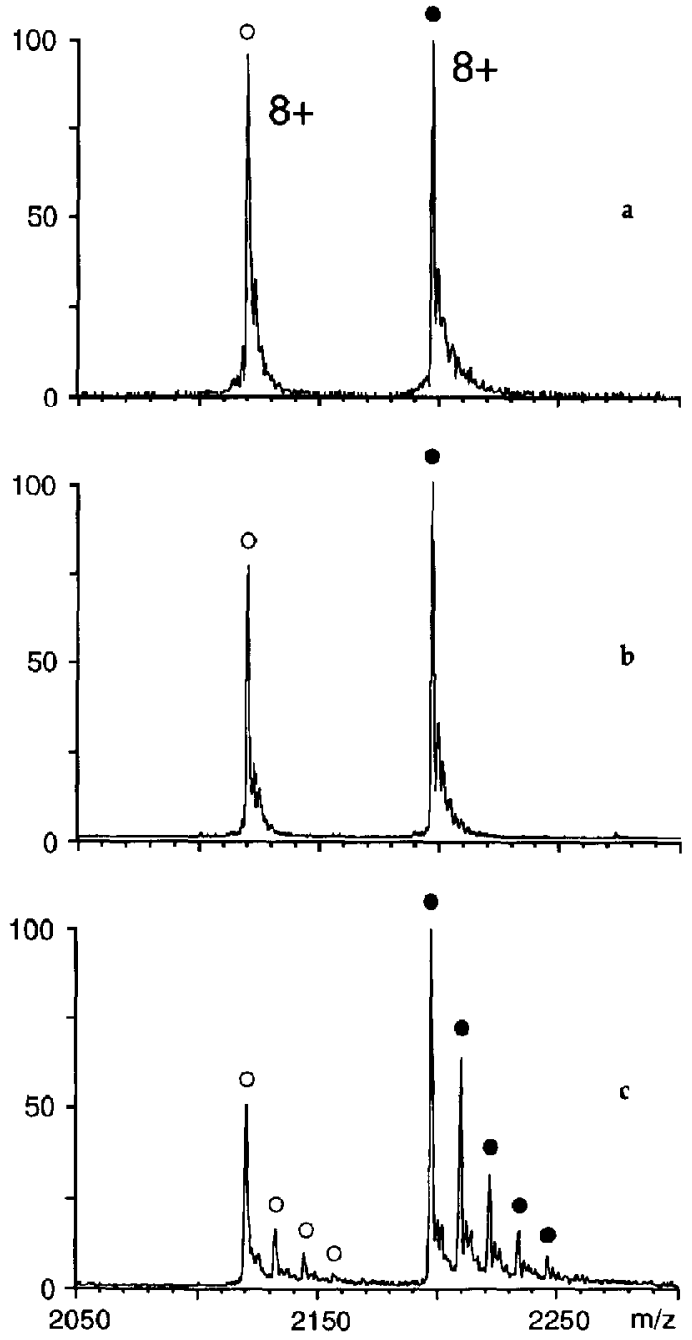

Figure 4. Collisional release of the heme group from the ions of (a) the equine myoglobin renatured at $\mathrm{pH} 8$ by adding ammonium hydroxide and (b) the pure and (c) the sulfate-infested native equine myoglobin at $\mathrm{pH} 7$ in $10 \mathrm{mM}$ ammonium acetate buffer. The partial spectra at mass-to-charge ratio 2050-2300 that contain the peaks of the $8^{+}$ions are shown. To effect gas-phase activation in the atmosphere/vacuum interface region, the bias voltage on the instrument orifice was raised from $+80 \mathrm{~V}$, the usual operating voltage for myoglobin ions, to $+150 \mathrm{~V}$ in $\mathbf{a}$ and $\mathbf{b}$ and to $+130 \mathrm{~V}$ in $\mathrm{c}$. The energized ion-molecule collisions between the myoglobin ions and the nitrogen curtain gas dissociated a fraction of the globin/heme complex (O), producing the lower mass (heme-less) ions $(O)$. In $c$, the marked tailing peaks in the two peak clusters were caused by the successive attachment of a sulfate (mass $98 \mathrm{Da}$ ) to the two leading $8^{+}$bare ions; on gas-phase activation, some myoglobin ions released the heme group but retained their noncovalently bound sulfate adduct(s). The collisional removal of the heme group for all three samples and the stripping of the sulfate adducts in c became complete at the orifice voltage $+200 \mathrm{~V}$.
$\mathrm{pHs}$ remained noncovalent in nature. Once unfolded, the polypeptide chain of myoglobin, which has 10 disulfide cross-linkage, possesses little binding affinity toward the heme group. Therefore, repossession of the heme group at the near-neutral $\mathrm{pHs}$ occurred most likely because the functional secondary and tertiary structures, and thus the hemebinding pocket, had been restored from the unfolded polypeptide chain.

At $\mathrm{pH} \mathrm{5,} \mathrm{the} \mathrm{myoglobin} \mathrm{polypeptide} \mathrm{chain} \mathrm{may}$ have refolded or partially refolded to form a compact structure similar to that of the native myoglobin, as suggested by the appearance of the nativelike, yet heme-less, charge-state distribution (Figures $2 \mathrm{c}$ and 3a); however, the inability of this intermediate "nativelike" state to retain the heme group also points out that at $\mathrm{pH} 5$, the fine structures around the heme-binding pocket are still not in exactly the right order to effect the tight "lock-and-key" fitting between this newly folded polypeptide chain and the heme group (possibly because one of the interior His residues remains protonated). Rebinding of heme at $\mathrm{pH}$ 6-8 suggests that some subtle structural and/or charge changes induced by the further $\mathrm{pH}$ increase have made the heme fitting within the myoglobin cavity much tighter, thus enabling the protein to retain the heme group with greater efficiencies.

It is very clear that the $\mathrm{pH}$ increase has caused the reverse structural changes (i.e., renaturation) of the acid-denatured myoglobin; however, the role of the heme group during this molecular transition remains obscure. Being concomitant with the polypeptide chain in the denatured myoglobin solution, the heme group could be either actively involved or a passive entity during the initial refolding of the polypepticle chain. In the former scenario, the heme group could possibly serve as a core for the myoglobin polypeptide chain to wrap around. If this were the case, the polypeptide chain either would not refold or would misfold in the absence of the heme group (e.g., the polypeptide chain of cytochrome $c$ relaxes into a random coil once its heme group is removed [41, 42]). To check whether the heme group is required to initiate the refolding of the myoglobin polypeptide chain, a parallel base-induced "renaturation" experiment was also performed on apomyoglobin in which the noncovalently bound heme group had been removed [39] by solvent exIraction. As seen in Figure 5, adding ammonium hydroxide produced a similar upward mass-to-charge ratio shift for the charge-state distribution of the apomyoglobin that was dissolved in $10 \%$ acetic acid. This experiment strongly suggests that the chain refolding of the aciddenatured myoglobin in solution does not require the assistance of the heme prosthetic group. It also shows that in the absence of the heme group, apomyoglobin alone can maintain a nativelike structure (although it appears that the heme-less molecule is conformationally less stable than its heme-containing counterpart, as evidenced by the presence of a small amount of 


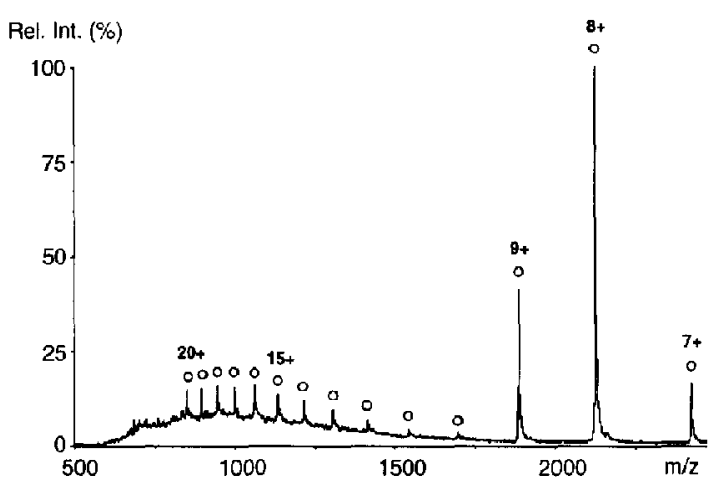

Figure 5. Electrospray mass spectrum of "renatured" equine apomyoglobin. The heme-less protein was first dissolved in $10 \%$ acetic acid solution (which gave a spectrum similar to that shown in Figure $2 b$ ), and then the solution $\mathrm{pH}$ was raised to 8 by adding ammonium hydroxide. The new charge-state distribution $\left(7^{+}-9^{+}\right)$ became predominant after raising the solution $\mathrm{pH}$.

denatured high-charge-state ions in the mass-to-charge ratio range $800-1600$ in Figure 5). This is in accordance with other conformational studies using proton nuclear magnetic resonance $[6,9]$, stopped-flow absorption [7], fluorescence [7], and circular dichroism $[6,7]$ techniques that under the conditions stabilizing the native conformation, apomyoglobin retains as much as $70 \%-80 \%[6,43]$ of the original secondary structure, and its tertiary structure is highly similar to that of the native myoglohin. Because this intermediate nativelike globular structure is stable enough to be isolated in various experiments, it must occupy one of the global minima on the myoglobin conformational potential energy surface.

Altogether, the ES/MS results suggest that the renaturation process of the acid-denatured myoglobin consists of two major steps in which the relaxed polypeptide chain first refolds itself into a nativelike compact structure, and then the heme prosthetic group, whose assistance is not required during the initial chain refolding, refits into the binding cavity of the newly folded polypeptide chain. Such a slepwise renaturation mechanism is consistent with the observation made in an earlier optical study $[44,45]$ in which a discrepancy between the optical rotation measurement and the optical density measurement was discovered. The optical rotation method, which determined the $\alpha$-helical content of the polypeptide chain, showed that in the transition $\mathrm{pH}$ region, the acid-denatured myoglobin refolded on the time scale of a few milliseconds; however, the optical density method, which directly monitored the fraction of the heme group relodged within the myoglobin binding cavity, gave a much slower rate, on the time scale of several minutes, indicating that the heme reattachment occurred much later in the time course of myoglobin renaturation.

\section{Conclusions}

This study demonstrates that ES/MS can be used to monitor the refolding process of a denatured protein. The ES/MS results show that renaturation of acid-denatured myoglobin is stepwise, consisting of two major steps: refolding of the relaxed polypeptide chain into a compact nativelike structure, in which the assisLance of the heme prosthetic group is nol required, and refitting of the heme group into the newly formed binding cavity. This study also shows that inclusion of a stabilizing buffer, such as ammonium acetate, in the protein solution is greatly beneficial to ES/MS detection of the intact ions of the noncovalent globin/heme complex.

\section{Acknowledgment}

We are grateful to Dr. S. Y. Yue for providing computer-aided graphical analysis of myoglobin $x$-ray structure.

\section{References}

1. Branden, C.; Tooze, J. Introduction to Protein Structure, Garland: New York, 1991.

2. Lehninger. A. L. Biochemistry, 2nd ed.; Worth: New York, 1975; pp 125-154.

3. Ghélis, C.; Yon, J. Protein Folding, Academic Press: New York, 1982.

4. Rossmann, M. G.; Argos, P. Annu. Rev. Biochem. 1981, 50, $497-532$.

5. Georgiou, G.; De Bernardez-Clark, E., Eds. Protein Refolding, ACS Symposium Series 470, Anterican Clenuical Suciely: Washington, DC, 1991.

6. Hughson, F. M.; Wright, P. E.; Baldwin, R. L. Science 1990, $249,1544-1548$

7. Kawamura-Konishi, Y.; Kihara, H.; Suzuki, H. Eur. J. Biochem. $1988,170,589-595$.

8. Lecomte, J. T. J; Cocco, M. J. Biochemistry 1990, 29, $11057-11067$.

9. Cocco, M. J.; Lecomte, J. T. J. Biochemistry 1990, 29, 11067-11072.

10. Barker, P. D.; Mauk, A. G. I. Am. Chem. Soc. 1992, 114, 3619-3624.

11. Bixler, J.; Bakker, G.; McLendon, G. J. Am. Chem. Soc. 1992, $114,6938-6939$.

12. Dole, M.; Mack, L. L.; Hines, R. L; Mobley, R. C; Ferguson, L. D.; Alice, M. B. J. Chem. Phys. 1968, 49, 2240-2249.

13. Fenn, J. B.; Mann, M.; Meng, C. K.; Wong, S. F.; Whitehouse, C. M. Science $1989,246,64-71$.

14. Smith, R. D.; Loo, J. A.; Ogotzalek Loo, R. R.; Busman, M.; Udseth, H. R. Mass Spectrom. Rev. 1991, 10, 359-452.

15. Chait, B.; Kent, S. B. H. Science, 1992, 257, 1885-1894.

16. Covey, T. R.; Bonner, R. F.; Shushan, B. I.; Henion, J. Rapid Commun. Mass Spectrom. 1988, 2, 249-256.

17. Henry, K. D.; Quinn, J. P.; McLafferty, F. W. J. Am. Chem. Soc. 1991, 113, 5447-5449.

18. Feng, R.; Konishi, Y.; Bell, A. W. J. Am. Soc. Mass Spectrom. 1991, 2, 387-401.

19. Feng, R,; Konishi, Y. Anal. Chem. 1992, 64, 2090-2095.

20. Loo, J. A.; Edmonds, C. G.; Smith, R. D. Anal. Chem. 1991, 63, 2488-2499. 
21. Loo, J. A.; Quinn, J. P.; Ryu, S. I.; Henry, K. D.; Senko, M. W.; McLafferty, F. W. Proc. Natl. Acad. Sci. USA 1992, 89, 286-289.

22. Feng, R.; Konishi, Y. Anal. Chem. 1993, 65, 615-619.

23. Covey, T. R.; Huang, E. C.; Henion, J. D. Anal. Chem. 1991, $63,1193-1200$.

24. Stevenson, D. E.; Feng, R.; Storer, A. C. FEBS Lett. 1990, 277, 112-114.

25. Stevenson, D. E.; Feng, R.; Dumas, F.; Groleau, D.; Mihoc, A.; Storer, A. C. Biotechnol. Appl. Biochem. 1992, 15, 283-302.

26. Ménard, R.; Feng, R.; Storer, A. C.; Robinson, V. J.; Smith, R. A.; Krantz, A. FEBS Lett. 1991, 295, 27-30.

27. Feng, R.; Yuan, Z. Proceedings of the 38th ASMS Conference on Mass Spectrometry and Allied Topics; Tucson, AZ, June 3-8, 1990; pp 998-999.

28. Ganem, B.; Li, Y.-T.; Henion, J. D. J. Am. Chem. Soc. 1991 , $113,7818-7819$.

29. Chowdhury, S. K.; Katta, V.; Chait, B. T. J. Am. Chem. Soc. 1990, 112, 9012-9013.

30. Katta, V.; Chait, B. T. J. Am. Chem. Soc. 1991, 113, 8534-8535.

31. Mizra, U. A.; Cohen, S. L.; Chait, B. T. Anal. Chem. 1993, 65 $1-6$.

32. Loo, J. A.; Ogorzalek Loo, R. R.; Udseth, H. R.; Edmonds, C. G.; Smith, R. D. Rapid Commun. Mass Spectrom. 1991, 5, 101-105.
33. Le Blanc, J. C. Y;; Beuchemin, D.; Siu, K. W. M.; Guevremont, R.; Berman, S. S. Org. Mass Spectrom. 1991, 26, 831-839.

34. Feng, R.; Konishi, Y. Proceedings of the 39th ASMS Conference on Mass Spectrometry and Allied Topics, Nashville, TN, May 19-24, 1991; pp 1432-1433.

35. Kendrew, J. C.; Dickerson, R. E.; Strandberg, B. E.; Hart, R. G.; Davies, D. R.; Phillips, D. C.; Shore, V. C. Nature 1960, $185,422-427$

36. Stryer, L. Biochemistry; W. H. Freeman: New York, 1988; pp 29-30, 143-174.

37. Takano, T. J. Mol. Biol. 1977, 110, 537-568.

38. Evans, S. V.; Brayer, G. D. J. Biol. Chem. 1988, 263, 4263-4268.

39. Rothgeb, T. M; Gurd, F. R. N. In Methods in Fnzymology, Vol. 52, Biomembranes, Part C; Fleischer, S.; Packer, L., Eds.; Academic: New York, 1978; pp 473-486.

40. Chowdhury, S. K.; Katta, V.; Beavis, R. C.; Chait, B. T. J. Am. Soc. Mass Spectrom. 1990, 1, 382-388.

41. Stellwagen, E.; Rysavy, R.; Babul, G. 1. Biol. Chem. 1972, 247, 8074-8077.

42. Fisher, W. R.; Taniuchi, H.; Anfinsen, C. B. J. Biol. Chem. $1973,248,3188-3195$.

43. Harrison, S. C.; Blout, E. R. J. Biol. Chem. 1965, 240, 299-303.

44. Shen, L. L.; Hermans, J. Jr. Biochemistry 1972, 11, 1842-1844.

45. Shen, L. L.; Hermans, J. Jr. Biochemistry 1972, 11, 1845-1849. 